\title{
Impact of Interpersonal Relationship on Risks Associated with Substance Abuse Among Senior Secondary School Students in Borno State, Nigeria
}

\author{
O.L, BADAKI ${ }^{1} \quad$ K.G. MOHAMMED ${ }^{2} \quad$ K, ABDULKADIR ${ }^{2}$ \\ 1.Department of Science Education, Federal University Dutsin-Ma, Katsina State, Nigeria \\ 2.Department of Physical and Health Education, University of Maiduguri, Borno State, Nigeria
}

\begin{abstract}
This study examined the impact of inter-personal relationship risks associated with substance abuse among senior secondary school students in Borno State. The population of the study comprised 25,580 senior secondary school students in Borno State. The schools were stratified into urban and rural. Borno State has a total of 73 schools comprising urban with 48 and rural schools with $25.40 \%$ of the samples were drawn from the population. Thus, 29 schools were selected using simple random sampling technique of fish bowl method to draw 19 urban and 10 rural schools. $10 \%$ of the respondents were drawn from the entire population of 25,580 which comprised 15,572 males from single schools, 603 females also from single schools and 398 from mixed schools. A total of 2,558 copies of questionnaire were administered while 2,542 were retrieved. A researcher developed questionnaire was used as instrument for data collection and a reliability index of 0.76 was obtained after pilot tested. Frequency counts and percentages were used to analyse responses. A two-way Factorial Analysis of Variance was used to test the null hypotheses and pair wise comparison test was used to determine where differences existed at 0.05 level of significance. The findings revealed that significant differences existed between school location (urban/rural) and gender (male/female) students in their interpersonal relationship risk associated with substance abuse. It was recommended among others that, the school authority should advice the students to imitate good behaviour from parents, relatives and friends; and Students should be guided to make friends who are of good character and behaviour.
\end{abstract}

Keywords: Impact, Interpersonal Relationship, Risk Associated, Substance Abuse

DOI: $10.7176 / \mathrm{JEP} / 11-8-09$

Publication date:March $31^{\text {st }} 2020$

\section{Introduction}

Interpersonal relationship encompasses several branches of social sciences, including discipline such as sociology, psychology, anthropology and social work. The term relates to association between two or more people that may range from fleeting to enduring. This association is based on love and liking regular business interactions, or other types of social commitments. The interpersonal relationships often occur in a variety of contexts such as the family, friends, marriages, associates, work, clubs, community, neighbourhood and so on. These relationships usually involve some levels of interdependence, (Caroline, Stephanie, \& Karin 2009). People in a relationship tend to influence each other, share their thoughts and feelings and engage in activities together because of interdependence. The most things that change or impact one member of the relationship will have some level of impact on the other member (Caroline, Stephanie, \& Karin 2009).

Khadia. and Michael, (2009) stated that interpersonal relationship has a risk factor of substance abuse in the community which have joined education and jobs status to share genetic influence with drug abuse and dependence. The negative interactions with friends and relatives share genetic factors with the use of drugs but the escalation from drugs to abusing them appear to generate discord between the abuser friends and relatives in casual fashion.

The United Nations Drug Control Programme (UNDCP) (1995) revealed that, interpersonal violence and substance abuse are major public health challenges that are strongly linked with one another. The involvement in drug use can increase the risk of being both a victim and/or perpetrator of violence, while experiencing violence can increase the risk of initiating substance abuse. The impact of drug-related interpersonal violence can be substantial, damaging individual's health and the cohesion and development of communities. It may also shift resources from other priorities, particularly with health and criminal justice service. Globally, interpersonal violence accounts for around half a million deaths per year. In every death there are many more victims affected by violence physically, socially, psychologically, emotionally and financially. The United Nation's division of narcotic drugs reported that never before have there been so many young people, even children, flirting with drugs and their associated hazards (Atoyebi, \& Atoyebi, 2013).

Likewise, Jeffery, Klein and King (2002) shows that, risk factors for substance related interpersonal violence are usually linked to gender, age and gang membership. In addition, Barbara (2000) suggested that, substance abuse changes people's approach and experience interactions, thus, adolescents psychological and social development is compromised as the formation of a strong self-identity. Likewise, Katz, Frome. and Amico (2000) 
on effects of outcome expectancies and personality on young adults on illicit drug use, heavy drinking and risky sexual behaviour, revealed that, college-aged social drinkers were 52.7 percent women and 47.3 percent men while the result indicated significant relationships between personality and substance abuse as well as gender differences. The indication was that; negative affectivity was related to greater substance abuse but not alcohol use or smoking.

Hence, the Nigeria, Drug Enforcement Administration (1995) conducted a household survey and reported that, adolescents who use alcohol and abuse substance are more likely than others to engage in sexual intercourse and other risky behaviours; a positive correlation has been demonstrated between alcohol use and frequency of sexual activity. The study concluded that, a sense of empowerment from healthy personal development from substance using individual is likely to acquire a superficial false and self- image.

The Nigerian National Drug Law Enforcement Agency (NDLEA) has stated that drug abuse

is a major problem in schools. For instance, about $20 \%$ of the school population in Lagos state, Nigeria had taken a psychoactive drug once in their lives. Many of these behaviours are heavily tied to the peer culture, as children learn from and imitate the peers they like and admire (Atoyebi \& Atoyebi, 2013).

Thus, the fore-going discussion necessitate the need to examine the interpersonal risks factor associated with substance abuse among senior secondary school students in Maiduguri, Borno State, Nigeria.

\section{Statement of the Problem}

In Borno State be it at urban or rural settlement there is an increasing number of youths of secondary school age whose interest is to abuse substances either due to lack of good parental background, influence from peer groups, ignorance, poverty or lack of employment which in turn led many of them to unproductive state of life. It has also been observed that from various advert programmes on media houses on the abuse of substance such as cigarette smoking, alcoholism and drugs, substance abuse seems to be on the increase among youths both at urban and rural settlement. Quite a good number of youths seem to be attracted to indiscriminate use of substances such as valium, tramadol, codeine, tutolin, and heroin believing that, such substances can positively contribute to their wellbeing and improve their academic performance. However, prolonged abuse of these substances has negative consequences on health, social interactions and psychological wellbeing as well as students' performance in schools. Prevalence of substance abuse among students seem to have reach an alarming proportion and has been identified as one of the pandemic health problems in Nigeria which demand urgent attention. Youths were more predisposed to substance abuse by various risks which result to different consequences in the society. In Borno State, many risky situation such as insecurity, lack of good parental care, lack of employment, increase in population, peer group influence, increase number of drug hawkers on streets, availability of substances, easy accessibility to substances, poverty and ignorance, promote substance abuse among youths including secondary school age students. Such risk factors lead to different consequences which include physical injuries, aggressiveness, anxiety, juvenile delinquency, indiscriminate sexual activities, unwanted pregnancies and spread of sexually transmitted diseases. This problem further leads the youth to more problematic behaviours like cultism, stealing, bullying and poor personal hygiene, which manifest itself into poor academic performance in schools. This study was then undertaken to examine the impact of inter-personal relationship risks associated with substance abuse among senior secondary school students in Borno State, Nigeria.

\section{Methodology}

Ex-post facto research design was used to investigate possible cause and effect by observing an existing condition (Gay, 1992). The population of the study comprised 25,580 senior secondary school students in Borno State. The schools were stratified into urban and rural. Borno State has a total of 73 secondary schools comprising urban with 48 and rural schools with $25.40 \%$ of the 73 schools were drawn from urban and rural schools. Thus, 29 schools were selected using simple random sampling technique of fish bowl method to draw 19 urban and 10 rural schools. $10 \%$ of the respondents were drawn from the entire population of 25,580 students which comprised 15,572 males from single sex school, 603 females and 398 mixed schools. The 10\% sample size is line with Ejifugha (1998) that 10 percent of a large population is fair enough sample size for a survey. A researcher - developed questionnaire which was structured on five (5) point Likert-scale response modes was used. The questionnaire was tested and a reliability coefficient of 0.76 Cronbach's Alpha was obtained. A total of 2,558 copies of questionnaire were administered while 2,542 were retrieved. The administration was done by the researcher and five trained research assistants in each of the schools selected. A systematic sampling method was adopted by given a copy of the questionnaire to every $3^{\text {rd }}$ respondent on the assembly ground in the morning in each of the selected schools until the expected samples were exhausted. Frequency counts and percentages were used to describe responses on interpersonal relationship risk factors of substance abuse, while a two-way Factorial Analysis of Variance was used to test the null hypothesis and Pair wise comparison test was used to determine where differences existed at 0.05 alpha level.

Objective: To examine the interpersonal relationship risk associated with substance abuse among senior secondary school students in Maiduguri, Borno State, Nigeria. 
Specific Objective: To determine the impact of inter-personal relationship risks associated with substance abuse among senior secondary school students in Borno State, Nigeria.

Research Question: What are the interpersonal relationship risks associated with substance abuse among senior secondary school students in Maiduguri, Borno State, Nigeria?

\section{Results and Discussion of Findings}

Table 1. Percentages of Interpersonal Relationship Risk Factor Associated with Substance Abuse.

\begin{tabular}{|c|c|c|c|c|c|c|}
\hline \multirow{3}{*}{$\mathbf{S} / \mathbf{N}$} & \multirow{3}{*}{ Items(risk factors) } & \multicolumn{5}{|c|}{$(n=2542)$} \\
\hline & & \multicolumn{5}{|c|}{ Responses } \\
\hline & & SD & D & $\mathbf{U}$ & $\mathbf{S A}$ & \\
\hline 1 & $\begin{array}{l}\text { Lack of parental } \\
\text { discipline exposes } \\
\text { students to abuse } \\
\text { drugs. }\end{array}$ & $44(2 \%)$ & $273(11 \%)$ & $328(13 \%)$ & $1438(57 \%)$ & $459(18 \%)$ \\
\hline 2 & $\begin{array}{l}\text { Conflict in a family } \\
\text { exposes students to } \\
\text { abuse drugs. }\end{array}$ & $44(2 \%)$ & $103(4 \%)$ & $315(12 \%)$ & $1649(65 \%)$ & $431(17 \%)$ \\
\hline 3 & $\begin{array}{l}\text { Parental } \\
\text { mismanagement } \\
\text { exposes students to } \\
\text { abuse drugs. }\end{array}$ & $48(2 \%)$ & $541(21 \%)$ & $246(10 \%)$ & $1338(53 \%)$ & $369(15 \%)$ \\
\hline 4 & $\begin{array}{l}\text { Friends influence } \\
\text { students to abuse } \\
\text { drugs. }\end{array}$ & $31(1 \%)$ & $164(7 \%)$ & $158(6 \%)$ & $1198(47 \%)$ & $991(39 \%)$ \\
\hline
\end{tabular}

The result of table 1 above showed that, $44(2 \%)$ of the respondents strongly disagreed that lack of parental discipline exposes students to abuse drugs, 273 (11\%) of the respondents disagreed with the statement, 328 (13\%) of the respondents were undecided, $1438(57 \%)$ of the respondents agreed that lack of parental discipline exposes students to abuse drugs, while $459(18 \%)$ of the respondents strongly agreed with the view.

Likewise, on item 2 of Table 1 indicated that, $44(2 \%)$ of the respondent strongly disagreed that conflict in a family make students to abuse drug, 103 (4\%) of the respondent disagreed with the statement, $315(12 \%)$ of the respondents were undecided, $1649(65 \%)$ of the respondents agreed that conflict in a family exposes students to abuse drugs while $431(17 \%)$ of the respondents strongly agreed with the statement. Item 3 also showed that, 48 $(2 \%)$ of the respondents strongly disagreed that, parental mismanagement exposes students to abuse drugs, 541 $(21 \%)$ of the respondents disagreed with the view, $246(10)$ of the respondents were undecided, $1338(53 \%)$ of the respondent agreed with the statement while 369 (15\%) of the respondents strongly agreed with the view. Finally item 4 indicated that, 31 (1\%) of the respondents strongly disagreed that, friends influence students to abuse drugs, $164(7 \%)$ of the respondents disagreed with the view, $158(6 . \%)$ of the respondent were undecided, $1198(47 \%)$ of the respondents agreed that friends influence students to abuse drugs while 991 (39\%) of the respondents strongly agreed with the view. The result in table 1 therefore revealed that lack of parental discipline, conflict in a family, parental mismanagement and influence of friends are all predisposing factors that leads students to abuse drugs.

\section{Hypothesis Testing}

There is no significant difference in the interpersonal relationship risk associated with substance abuse between urban/rural, male/female senior secondary school students in Maiduguri, Borno State, Nigeria.

Table 2. Two-way Factorial Analysis of Variance examining interpersonal relationship risk associated with substance abuse among urban/rural and male/female student

\begin{tabular}{llllll} 
& & & \multicolumn{2}{c}{$\mathrm{n}=2542$} \\
\hline Source & Sum of Square & Df & Mean square & F & Sig. \\
\hline School Location & 78.492 & 1 & 78.492 & 16.237 & .000 \\
Gender & 613.343 & 1 & 613.343 & 126.880 & .000 \\
School Loc *Gender & 495.154 & 1 & 495.154 & 102.431 & .000 \\
Error & 12268.814 & 2538 & 4.834 & & \\
Total & 13437.487 & 2541 & & & \\
\hline
\end{tabular}

Table 2 showed that significant difference existed between school location (urban and rural) and gender (male and female) students in their interpersonal relationship risk associated with substance abuse. This therefore shows that the null hypothesis is rejected. 
Table 3. Result of pair wise comparison of honestly significant difference on interpersonal relationship risk factor associated with substance abuse between school location and gender.

\begin{tabular}{ccccccc}
\hline Group & N & Mean & SD & Mean Difference & HSD & Statistical Decision \\
\hline Urban Male & 665 & 14.39 & 1.99 & & & \\
Urban Female & 509 & 16.27 & 1.78 & 1.88 & 0.33 & $\mathrm{H}_{05}$ Rejected \\
Urban Male & 665 & 14.39 & 1.99 & & & \\
Rural Male & 746 & 15.63 & 2.46 & 1.24 & 0.30 & $\mathrm{H}_{05}$ Rejected \\
Urban Female & 509 & 16.27 & 1.78 & & & \\
Rural Male & 746 & 15.63 & 2.46 & 0.64 & & $\mathrm{H}_{05}$ Rejected \\
Urban Female & 509 & 16.27 & 1.78 & & 0.32 & $\mathrm{H}_{05}$ Rejected \\
Rural Female & 622 & 15.73 & 2.38 & 0.54 & & \\
Rural Male & 746 & 15.63 & 2.46 & & & $\mathrm{H}_{05}$ Rejected \\
Rural Female & 622 & 15.73 & 2.38 & 0.10 & & $\mathrm{H}_{05}$ Rejected \\
Urban Male & 665 & 14.39 & 1.99 & & 0.31 & \\
Rural Female & 622 & 15.73 & 2.38 & 1.34 & & \\
\hline
\end{tabular}

Table 3 shows the result of pair wise comparison of honestly significant difference of interpersonal relationship risk associated with substance abuse between school location (urban/rural) and gender (male and female students). The result indicated that there is significant difference between school location (urban and rural) school and gender (male/female) in the interpersonal relationship risk associated with substance abuse. Significant difference also existed in the interaction effect of school location and gender in the interpersonal relationship risk associated with substance abuse.

To locate were the differences existed using honestly significant difference test indicated that, urban male and urban female, urban male and rural male, urban female and rural male, urban female and rural female and urban male and rural female differed significantly in their interpersonal relationship risk associated with substance abuse. Thus, the null hypothesis was rejected.

\section{Discussion of Findings}

Findings of this study also revealed that, lack of parental discipline, conflict in family and parental mismanagement could all influence students to abuse substance. This finding conformed with Khadia, Micheal and David (2009) who stated that, individual's social situation such as, relationship with parents, friends and family or other close relatives were addressed as interpersonal risk associated with substance abuse. Similarly, lack of parental discipline, family cohesion and deficient parental monitoring are interpersonal relationship risk associated with substance abuse. Kafur and Creamer (2001) stated that, attitude, behaviour, negative family environment, substance related problems in parental and siblings, single parents home are all interpersonal risk associated with substance abuse.

The findings also indicated that, students abuse substance when imitating peer groups and models in the society. This is in line with Nigerian Drug Enforcement Administration (N.D.E.A) (1995) which stated that, social role modeling within immediate environment or over media such as television serve as social influence, such leads individuals to indulge to certain unwanted consequence like substance abuse, examples of people from whom others imitate and take to their steps in substance abuse include, Bob Marley, Sly Dumber, Jimmy Hendrix, Bobby Brown, Ben Johnson and Maradona who have all attempted to abuse substance as a means of enhancing performance. Furthermore, National Narcotics Intelligence Consumers Committee (N.N.I.C.E) (1996) stated that, consequences of substance abuse within society include loss of job, family problem, school dropout, and criminal offences such as stealing, suicide, cultism, prostitution, rioting, protest and unjustifiable demonstration against authorities.

\section{Conclusion}

Based on the findings from this study, it was concluded that school location and gender have significant influence on student's predisposition to interpersonal relationship risk associated to substance abuse in selected secondary schools in Borno State, Nigeria.

\section{Recommendations}

Based on the findings of this study, the following recommendations were made:

1. Students should be guided to make friends who are of good character and behaviour;

2. The school authority should advice the students to imitate good behaviour from parents, relatives and friends;

3. Parents, teachers, school authorities and guidance counsellors should advise students not to abuse substances for it may lead to unimaginable health problems. 


\section{References}

Barbara, S. (2000). An explanatory multivariate approach to drugs consumption pattern in youth people based on primary socialization. Addition survey (cas) (2005). p.57.

Caroline, D., Stephanie, F., \& Karin, M. (2009). Production of alcohol addiction patient: University press USA.

Ejifugha, A.U (1998) Fundamentals of Research in Health Education. Barloz Publishers Inc. Owerri. Revised Ed. Nigeria. 23-24.

Jeffery, D. klein, A. \& king, 1. (2002) UK drug report on trends in 2001 (report from UK focal point to EMCDDA) London drug scope.

Gay, L.R (1992). "Educational Research: Competencies for Analysis and Application". Maxwell Macmillian International, New York. 114-115

Kafur, D, R \& Creamer, C, H. (2001) risk functions and prevention evidence based mental health 3, 70-71

Katz, E. Fromme, K. \& Amico, E. (2000). Effect of outcome expectancies and personality on young adults' substance use. Heavy drinking and risky sexual behaviour cognitive therapy and research 24, 1-22.

Khadia, N. Michael, 1. \& David, A. (2009). Ethic identification and perception of substance use.canadian journal of public health. Vol 96 no. 5 septoc 2009, pp. 340 - 343.

Nigeria Drug Enforcement Administration (1995). US Department of Justice. May 1995. DEA 1995,

National Narcotics Intelligence Consumers Committee. The report of 1995/96 Supply of Substance to United States.

Atoyebi, O.A. \& Atoyebi, O.E. (2013). Pattern of Substance Abuse among Senior Secondary School Students in Southern West Nigerian City. International Review of Social Sciences and Humanities. 4(2):54-65.

United Nation Drug Control Programme (UNDCP). (1995). Annual Field Report on Nigeria. Nigeria 1994-95; periodic report from field office in Nigeria. 